\title{
A AMÉRICA LATINA, A COVID-19 E AS MIGRAÇÕES FORÇADAS: PERSPECTIVAS EM MOVIMENTOS, MUROS EPIDEMIOLÓGICOS E SOMBRIAS IMAGENS
}

Latin America, COVID-19 and forced migration: perspectives on movements, epidemiological walls, and gloomy images

América Latina, COVID-19 y migración forzada: perspectivas sobre movimientos, muros epidemiológicos e imágenes sombrías

\author{
RAFAEL ARAUIO ${ }^{*}$ \\ ERICA SARMIENTO ${ }^{\mathrm{II} * *}$
}

DOI: https://doi.org/10.1590/S2178-149420210202

'Universidade do Estado do Rio de Janeiro - Rio de Janeiro (RJ), Brasil.

*Professor Adjunto de História da América da Universidade do Estado do Rio de Janeiro. Professor colaborador do Programa de Pós-Graduação em História Comparada da Universidade Federal do Rio de Janeiro (rafa.ara@gmail.com).

(D) https://orcid.org/0000-0001-7551-6448

"Universidade do Estado do Rio de Janeiro - Rio de Janeiro (RJ), Brasil.

**Professora adjunta de História de América da Universidade do Estado do Rio de Janeiro. Professora do Programa de Pós-Graduação em História Política da Universidade do Estado do Rio de Janeiro. Bolsista Produtividade CNPQ e Jovem Cientista do Nosso Estado FAPERJ (erisarmiento@gmail.com).

(D) https://orcid.org/0000-0001-6133-4328

Artigo recebido em 29 de dezembro de 2020 e aprovado para publicação em 11 de março de 2021. 


\title{
RESUMO
}

A América Latina tornou-se, em junho de 2020, um dos epicentros da pandemia. Embora concentremos aproximadamente $8 \%$ da população mundial, temos em torno de $20 \%$ dos casos e $30 \%$ das mortes causadas pela COVID-19. Um dos graves problemas enfrentados pelas populações latino-americanas são as migrações forçadas, que, assim como tudo o que diz respeito às populações vulneráveis, incrementou-se na pandemia. Os casos da América Central e do México, país considerado um dos maiores corredores humanos do mundo, alcançaram níveis impensáveis de violações de direitos humanos. Discutiremos neste artigo os efeitos políticos e socioeconômicos da pandemia decorrente do coronavírus da síndrome respiratória aguda grave 2 ([SARSCoV-2], causador da COVID-19) na América Latina. Igualmente, apresentaremos, por meio da imprensa e dos relatórios de organizações civis, como, em plena pandemia, acentuaram-se a criminalização e a culpabilização dos migrantes nos discursos dos órgãos governamentais estadunidenses.

PALAVRAS-CHAVE: América Latina; COVID-19; Migrações.

\begin{abstract}
Latin America became one of the epicenters of the pandemic in June 2020. Although concentrating approximately $8 \%$ of the world population, it comprises around $20 \%$ of cases and $30 \%$ of deaths caused by COVID-19. One of the serious problems faced by Latin American populations is forced migration, which, like everything that concerns vulnerable populations, has increased during the pandemic. The cases of Central America and Mexico, a country considered one of the largest human corridors in the world, reached unthinkable levels of human rights violations, as demonstrated. This article addressed the political and socioeconomic effects of the pandemic resulting from the SARS-CoV-2 virus (COVID-19) in Latin America. Likewise, the press and the reports of civil organizations present how, in the middle of the pandemic, the criminalization and blaming of migrants in the speeches of the American government agencies has been accentuated.
\end{abstract}

KEYWORDS: Latin America; COVID-19; Migrations.

\section{RESUMEN}

En junio de 2020, América Latina se convirtió en uno de los epicentros de la pandemia. Aunque concentramos aproximadamente el $8 \%$ de la población mundial, tenemos alrededor del $20 \%$ de los casos y el $30 \%$ de las muertes causadas por COVID-19. Uno de los graves problemas que enfrentan las poblaciones latinoamericanas es la migración forzada que, como todo lo que concierne a las poblaciones vulnerables, se ha incrementado con la pandemia. Los casos de Centroamérica y México demuestran eso, pues esta nación es considerada uno de los corredores humanos más grandes del mundo y alcanzó niveles impensables de violaciones de derechos humanos, demuestran eso.

PALABRAS CLAVE: América Latina; COVID-19; Migraciones Forzadas. 


\section{CONSIDERAÇÕES INICIAIS}

T mpulsionada pelo ciclo de exportação das commodities, entre 2003 e 2013, a América Latina experienciou uma década de consistente crescimento econômico, relativa estabilidade política e desenvolvimento de políticas públicas que contribuíram para que a pobreza, 0 desemprego e a desigualdade social retrocedessem'. Um símbolo dessa fase, que despertou esperança de um futuro mais igualitário e politicamente estável no Brasil e na região, foi a capa da revista The Economist2, em novembro de 2009. Sob o título "O Brasil decola", nela foi inserida uma montagem com o Cristo Redentor decolando, como um foguete.

Disseminou-se uma sensação de otimismo quanto à superação de mazelas históricas de nossas sociedades, como a miséria e as recorrentes crises políticas. Essa sensação de um futuro promissor e estável pôde ser observada em pesquisas de opinião acerca das nossas democracias elaboradas pela Corporación Latinobarómetro $(2018)^{3}$. A satisfação cidadã com as nossas democracias refletia a confiança com o presente e com o futuro. Em 2009 e 2010, alcançamos 0 maior índice de apoio as democracias em nossa região, como pode ser observado no Gráfico 1.

Esse cenário de otimismo começou a retroceder em 2014. Entre esse ano e 2019, a nossa média de crescimento econômico foi de 0,3\%. A fragilidade da expansão das economias locais contribuiu para a elevação do desemprego e da pobreza, além de acentuar a precarização do mercado de trabalho. Em 2019, por exemplo, cerca de 54\% da população

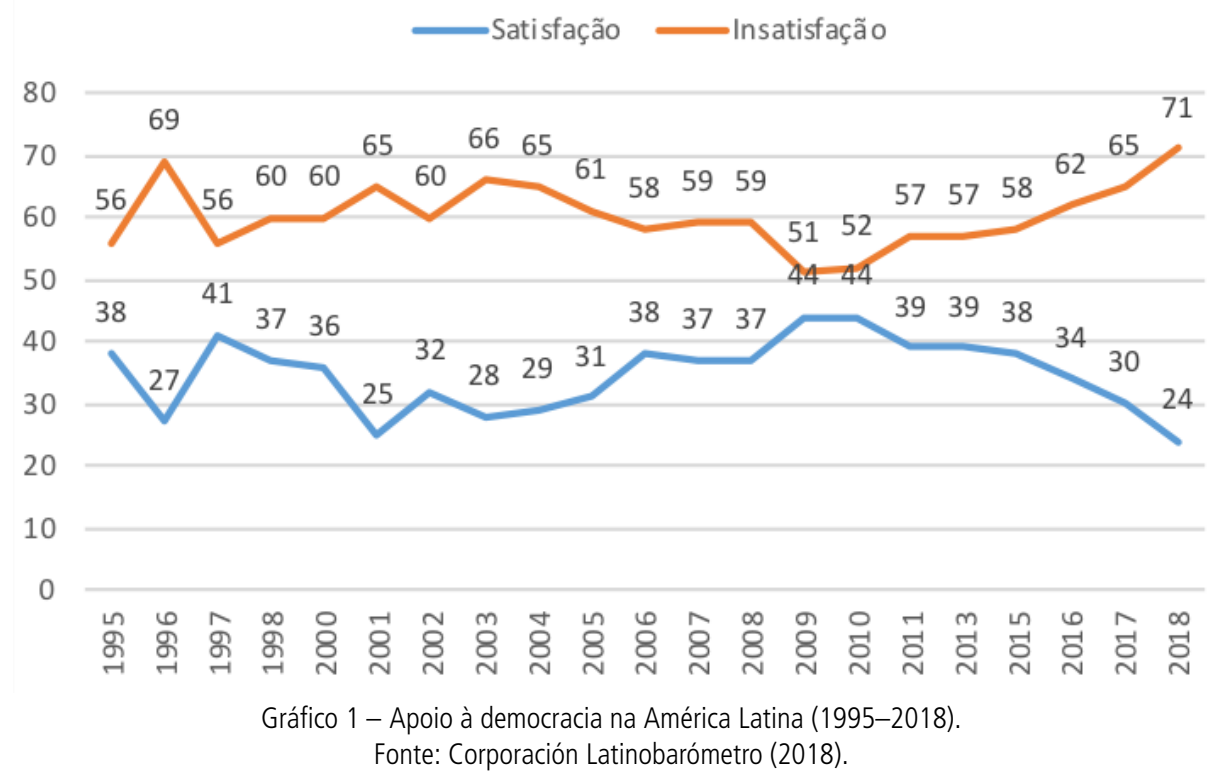


economicamente ativa (PEA), estava na informalidade. Em 2014, o percentual girava em torno de 47\%. Além disso, entre aqueles anos, em torno de 27 milhões de habitantes (4\% de nossos habitantes) ingressaram na situação de pobreza ${ }^{4}$. Essas informações podem ser observadas na Tabela 1.

Tabela 1 - Percentuais de desemprego, pobreza e crescimento do Produto Interno Bruto da América Latina entre 2014 e $2019^{5}$.

\begin{tabular}{|c|c|c|c|}
\hline Ano & Desemprego & PobrezA & CRescimento do PIB \\
\hline 2014 & 6,1 & 27,8 & 1,1 \\
\hline 2015 & 6,6 & 29,1 & $-0,2$ \\
\hline 2016 & 7,9 & 30,0 & $-1,2$ \\
\hline 2017 & 8,1 & 30,1 & 1,1 \\
\hline 2018 & 8,1 & 30,1 & 0,9 \\
\hline 2019 & 8,0 & 30,8 & 0,1 \\
\hline
\end{tabular}

Fonte: Elaboração dos autores.

PIB: Produto Interno Bruto.

O retrocesso socioeconômico após 2014 submergiu a confiança com o futuro da região, contrastando com o diagnóstico do fim da primeira década do século XXI. Como exemplo, recorremos, mais uma vez, às informações do Informe Latinobarómetro. Como pode ser observado no Gráfico 1, a repulsa às nossas democracias saltou a partir de 2013, alcançando 71\% de insatisfeitos, maior índice da série, que foi iniciada em 1995.

0 mal-estar gerado pelas dificuldades de acesso ao mercado de trabalho, o recuo dos índices sociais e o estancamento da expansão econômica auxiliaram no desgaste dos sistemas políticos locais e da doutrina neoliberal. Combinados, esses fatores colaboraram para as ondas de rebeliões ${ }^{6}$ populares ocorridas no segundo semestre de 2019 em países como Colômbia, Equador, Haiti e Chile?

O baixo nível de confiança nas democracias possibilitou, ainda, o surgimento e/ou fortalecimento dos distintos grupos da direita regional. Como exemplos, citamos o fenômeno do bolsonarismo no Brasil e as pequenas organizações de extrema-direita, como o boliviano Resistencia Juvenil Cochala $(\mathrm{RJC})^{8}$. Este grupo é composto, majoritariamente, por jovens do departamento de Cochabamba. Na ocasião da crise política de 2019, que culminou na renúncia forçada do então presidente Evo Morales, ele foi responsável por um dos mais emblemáticos episódios de violência daqueles dias. Nos referimos ao sequestro e às agressões físicas e verbais perpetradas contra a prefeita da cidade de Vinto, Patrícia Arce Guzman (MAS). 
Ela teve o seu cabelo cortado e foi obrigada a caminhar pelas ruas daquela cidade pintada de vermelho e com gasolina ateada em seu corpo ${ }^{9}$.

Nessa cena, de requintes cruéis e desumanos, vemos uma clara demonstração da continuidade do patriarcado, da herança colonial e da supremacia do colonizador. As agressões contra uma mulher indígena, que exercia um cargo de autoridade, demonstram isso. Ao cortar seus cabelos, pretendiam excluí-la do universo feminino, humilhá-la e expulsá-la do que, para as mulheres latino-americanas, representa a beleza, a fertilidade e a feminilidade: os cabelos longos. As crises, à simples vista, podem ter causas imediatamente conjunturais, mas também envolvem fatores estruturais das sociedades, símbolos da continuidade que são reproduzidos nos comportamentos dos indivíduos em situações extremas, como as demonstrações de racismo que vivenciamos diariamente em nossos países. De acordo com Aníbal Quijano (2005), a ideia de raça é uma construção mental que expressa a experiência básica da dominação colonial e que, desde então, permeia as dimensões mais importantes do poder mundial, incluindo sua racionalidade específica, o eurocentrismo. Esse eixo tem, portanto, origem e caráter colonial, mas provou ser mais duradouro e estável que o colonialismo em cuja matriz foi estabelecido. Implica, consequentemente, em um elemento de colonialidade no padrão de poder hoje hegemônico (Calazans et al., 2019: 12).

Os efeitos da pandemia causada pelo coronavírus da síndrome respiratória aguda grave 2 ([SARS-CoV-2], causador da COVID-19) podem acentuar o nebuloso cenário de fortalecimento da direita latino-americana, tornando os nossos futuros político e socioeconômico imprevisíveis. Com isso, resquícios indesejáveis do nosso passado colonial, retratado na hostilidade perpetrada contra Patricia Arce Guzman, na Bolívia, podem, infelizmente, reproduzir-se.

Para 2020, estudos da Comissão Econômica para a América Latina e Caribe (CEPAL) utilizados nesse artigo vislumbram retração de 7,7\% do PIB regional, algo que consolidou uma nova década perdida, pois a renda per capita regredirá aos números de $2010^{10}$. 0 desemprego atingiu $10,4 \%{ }^{11}$ dos habitantes que buscam vagas no mercado de trabalho e a pobreza e a extrema pobreza alcançaram, respectivamente, em torno de 7,1 e 4,5\% dos nossos cidadãos. Ao final de 2020, em torno de 231 milhões de pessoas, um pouco mais de 1/3 dos latino-americanos, foram inseridos na condição de pobreza ou extrema pobreza ${ }^{12}$.

Em relação à educação, por exemplo, especialistas alertam que quase a metade das crianças das regiões consideradas mais pobres já abandonou a escola desde o início da pandemia. Um novo estudo do Banco Mundial ${ }^{13}$ adverte que América Latina enfrenta uma "catástrofe de desigualdade" relacionada com a crise educativa. Segundo o diretor do departamento de educação do Banco Mundial, Jaime Saavedra, ocorreu um aumento da pobreza no aprendizado escolar da América Latina em relação às outras regiões do mundo. A pandemia, 
dessa forma, só fez agudizar a crise educativa e o cenário alarmante em que vive a educação no continente latino-americano ${ }^{14}$.

Essas circunstâncias podem convulsionar ainda mais o já instável quadro político latino-americano. Mobilizações, como ocorridas em 2020, apesar do distanciamento social imposto pela pandemia, poderão acentuar-se. Na Bolívia, na Colômbia e no Chile já ocorreram inúmeras manifestações nas quais foram demandadas políticas públicas que mitiguem os efeitos econômicos e sociais da pandemia ${ }^{15}$.

0 caso brasileiro é similar ao dos nossos vizinhos, embora guardemos ares mais inquietantes devido a alguns fatores da nossa história recente. De 2011 a 2020, empobrecemos. Nessa nova década perdida, nosso PIB cresceu 2,2\%, enquanto a média global foi de 30,5\%. Nem na década de 1980 os números foram tão preocupantes. Naquela ocasião, expandimos o nosso produto interno em 16,9\%, enquanto o mundo alcançou 37,9\%. Em 2010, nossa renda per capita, com valores corrigidos, era de $\mathrm{R} \$ 36.245$. Ao fim de 2020 , ela girará em torno de $R \$ 34.101^{16}$. A debilidade econômica brasileira tende a incrementar o desemprego e a miséria, ampliando a vulnerabilidade de distintos segmentos sociais. Inevitavelmente, o mal-estar de parcelas da sociedade civil, externado após as jornadas de junho de 2013, e que foi aprofundado com a "tempestade perfeita" iniciada naquele ano, poderá aprofundar-se.

Diante dessa desalentadora conjuntura, cremos na necessidade de reflexões que contribuam para os estudos e debates desta fase imprevisível da história recente da América Latina. A pandemia expôs as consequências sociais oriundas da implementação das práticas políticas e econômicas neoliberais que se consolidaram na região entre as décadas de 1980 e 1990. 0 contexto lúgubre que vivemos expôs os grupos mais vulneráveis aos efeitos psicológicos e socioeconômicos da COVID-19. A transmissão do vírus não escolhe classe social e é democrática, mas os seus efeitos não os são. Como indicam os estudos cepalinos, afrodescendentes, indígenas, mulheres, migrantes e jovens das periferias latino-americanas são os mais impactados pela pandemia.

Dentro da situação de vulnerabilidade, existem aqueles que se encontram em trânsito, em movimento, em caminhos que, subitamente, pela pandemia, passaram a estar fechados, inaptos, obstaculizados. 0 que já era considerado uma crise - a migratória - com suas massivas e dramáticas diásporas no século XXI, passa a estar incluído em outra: a crise pandêmica. Em nome da emergência sanitária fecham-se as fronteiras, e milhares de latino-americanos se deparam com muros ou permanecem em um constante "estado de trânsito", à espera de uma solução dos estados receptores, de eles decidirem o que fazer com os seus destinos. 0 caso mais extremo são os do centro-americanos a caminho dos Estados Unidos. 
Não é um fato novo, como não o é a migração, mas sim o extremo grau de violência com que as políticas anti-imigrantistas do governo de Donald Trump tratou essa população, especialmente ao longo do ano de 2020. A chegada da pandemia só recrudesceu as violações de direitos humanos como as deportações em massa, o impedimento da entrada no país, 0 abandono dos migrantes em condições de extrema vulnerabilidade nas cidades de fronteira e a ocultação de crianças separadas de suas famílias. Atrocidades que o mundo e as potências ocidentais assistiram bestializadas, porém caladas, pois são vidas invisibilizadas, sem destino, paradas em meio à pandemia. Para muitos, representam corpos contaminados que incomodam, obstruindo as fronteiras.

Apresentaremos neste artigo as repercussões socioeconômicas da pandemia a partir dos estudos realizados ao longo de 2020 pela CEPAL, alguns deles em parceria com a Organização Internacional do Trabalho (OIT) e a Organização das Nações Unidas para a Educação, a Ciência e a Cultura (UNESCO). Avaliaremos, ainda, as migrações forçadas e os fluxos migratórios durante esse momento pandêmico, a partir da imprensa e dos relatórios de organizações civis e também governamentais. Assim, esperamos contribuir para as reflexões e os debates que ocorrem nas universidades e nas sociedades civis latinas sobre este momento tão trágico e excepcional.

\section{COVID-19 E OS SEUS EFEITOS SOCIAIS E ECONÔMICOS}

$\mathrm{O}$ ano de 2020 teve a maior retração do PIB mundial desde 1946. Países emergentes e desenvolvidos foram afetados pela queda generalizada da atividade econômica decorrente da pandemia. Encerramos 2020 com contração do comércio internacional e considerável redução de atividades econômicas nos setores de serviços. Embora pacotes fiscais e monetários na casa dos US $\$ 20$ bilhões, valores sem precedentes na história mundial, tenham sido implementados em escala global, eles não foram suficientes para impedir os impactos econômicos e sociais do SARS-CoV-217.

A América Latina tornou-se, em junho de 2020, um dos epicentros da pandemia. Embora concentremos aproximadamente $8 \%$ da população mundial, temos em torno de $20 \%$ dos casos e $30 \%$ das mortes causadas pela COVID-1918. Somos os mais afetados do mundo emergente. Problemas estruturais das nossas sociedades, como vulnerabilidade econômica, histórica desigualdade de renda; precária infraestrutura habitacional, ineficazes serviços públicos de fornecimento de água potável e tratamento de esgoto, bem como escassos mecanismos de proteção social aos grupos mais vulneráveis, auxiliam na compreensão do porquê de sermos um dos epicentros mundiais da pandemia. 
Esses elementos reafirmam a nossa crença de que a disseminação e os impactos do vírus não são democráticos. Não há horizontalidade, como podemos constatar a partir da leitura dos relatórios cepalinos utilizados nesta pesquisa. Como a comissão demonstra, as populações negra e indígena, as mulheres e os jovens das grandes periferias são os mais atingidos pelos múltiplos efeitos causados pela pandemia.

Apresentaremos a seguir informações aferidas a partir da leitura dos relatórios sobre os efeitos da COVID-19 divulgados pela CEPAL ao longo de 2020. Demonstraremos alguns dados e avaliações com o intuito de auxiliar as reflexões sobre os impactos da pandemia neste momento tão turbulento, anuviado e lutuoso que vivemos na América Latina e no mundo. Ao cooperarmos com a divulgação dessas investigações, acreditamos que auxiliaremos agentes públicos e segmentos da sociedade civil que desejem objetar os efeitos da COVID-19 em nossa região.

Nos estudos publicados entre abril e dezembro de $2020^{19}$, a CEPAL apontou algumas perspectivas acerca das múltiplas implicações da pandemia e do novo tempo que ela abrirá na América Latina. Sintetizamos abaixo algumas informações:

- Haverá um aumento da pobreza e da extrema pobreza, como pode ser observado na Tabela 2. Entre os fatores para isso, alguns deles já expostos, contribuirá, em especial, a redução das remessas financeiras realizadas por migrantes que residem nos Estados Unidos e na Europa;

- Esta crise, diferentemente das anteriores, teve significativas consequências no setor de serviços. 0 turismo foi o setor mais afetado em escala global. Entre janeiro e agosto, houve uma diminuição de aproximadamente $65 \%$ das atividades do setor. A sua retração impactou largamente as economias latino-americanas, em razão da relevância dessa atividade para as nossas economias;

- Os estratos populacionais que vivem em condições de insegurança econômica foram os mais afetados pela perda de renda. Em 2019, cerca de 47\% da nossa população, em torno de 283 milhões de pessoas, estavam inseridos nesse grupo, cujo ingresso per capita correspondia a até três vezes ao da linha de pobreza. Esse segmento não possuía reservas financeiras para enfrentar uma inesperada paralisia econômica. Por isso, este grupo foi largamente afetado pela pandemia e esteve entre os grupos que demandaram políticas públicas, fosse por meio da transferência direta de renda ou no auxílio a pequenas e médias empresas. A seguir, apresentamos na Tabela 3 as principais medidas adotadas com o intuito de apoiar esse e outras segmentos sociais onde poderá ser constatada a densidade de políticas públicas de apoio a esse bloco; 
Tabela 2 - América Latina (17 países): projeção da população em situação de pobreza extrema e pobreza, 2020 (Em porcentagens e pontos percentuais) ${ }^{20}$.

\begin{tabular}{|l|c|c|c|c|c|c|}
\hline País & $\begin{array}{c}\text { EXTREMA } \\
\text { PobreZA } \\
2019\end{array}$ & $\begin{array}{c}\text { EXTREMA } \\
\text { PoBREZA } \\
2020\end{array}$ & $\begin{array}{c}\text { VARIAÇÃO } \\
2019 \mathrm{E} \\
2020\end{array}$ & $\begin{array}{c}\text { PoBREZA } \\
2019\end{array}$ & $\begin{array}{c}\text { PoBREZA } \\
2020\end{array}$ & $\begin{array}{c}\text { VARIAÇÃO } \\
2019 \mathrm{E} \\
2020\end{array}$ \\
\hline Argentina & 3,8 & 6,9 & 3,1 & 26,7 & 37,5 & 10,8 \\
\hline Bolívia & 14,3 & 16,8 & 2,5 & 32,3 & 36,1 & 3,8 \\
\hline Brasil & 5,5 & 9,8 & 4,3 & 19,2 & 26,9 & 7,7 \\
\hline Chile & 1,4 & 3,4 & 2 & 9,8 & 15,5 & 5,7 \\
\hline Colômbia & 10,3 & 14,3 & 4 & 29 & 34,1 & 5,1 \\
\hline Costa Rica & 3,4 & 5,1 & 1,7 & 16,5 & 20,5 & 4 \\
\hline Equador & 7,6 & 12,7 & 5,1 & 25,7 & 32,7 & 7,0 \\
\hline El Salvador & 7,4 & 11,9 & 4,5 & 33,7 & 40,2 & 6,5 \\
\hline Guatemala & 19,8 & 22,7 & 2,9 & 48,6 & 51,6 & 3 \\
\hline Honduras & 18,7 & 22,2 & 3,5 & 54,8 & 59 & 4,2 \\
\hline México & 11,1 & 17,4 & 6,3 & 41,9 & 49,5 & 7,6 \\
\hline Nicarágua & 18 & 22,8 & 4,8 & 47,1 & 52,7 & 5,6 \\
\hline Panamá & 6,5 & 8,5 & 2 & 14,6 & 17,5 & 3,1 \\
\hline Paraguai & 6,2 & 6,6 & 0,4 & 19,4 & 20,9 & 1,5 \\
\hline Peru & 3,7 & 7,6 & 3,9 & 16,5 & 25,8 & 9,3 \\
\hline República Dominicana & 4,5 & 6,7 & 2,2 & 20,3 & 24,7 & 4,4 \\
\hline Uruguai & 4,5 & 6,7 & 2,2 & 20,3 & 24,7 & 4,4 \\
\hline América Latina & 11 & 15,5 & 4,5 & 30,2 & 37,3 & 7,1 \\
\hline
\end{tabular}

Fonte: elaboração dos autores.

Tabela 3 - América Latina e Caribe: medidas de proteção social para o combate aos efeitos da COVID-1921.

\begin{tabular}{|c|c|c|c|c|}
\hline $\begin{array}{l}\text { TRANSFERÊNCIAS } \\
\text { MONETÁRIAS }\end{array}$ & $\begin{array}{c}\text { TRANSFERÊNCIAS } \\
\text { EM PRODUTOS }\end{array}$ & $\begin{array}{l}\text { FORNECIMENTO DE SERVIÇOS } \\
\text { BÁSICOS POR MEIO DO NÃO } \\
\text { PAGAMENTO DE CONTAS }\end{array}$ & $\begin{array}{l}\text { PROTEÇÃO SOCIAL PARA } \\
\text { TRABALHADORES FORMAIS }\end{array}$ & $\begin{array}{l}\text { OUTROS APOIOS } \\
\text { DIRETOS A } \\
\text { FAMÍLIAS }\end{array}$ \\
\hline $\begin{array}{l}\text { Programas de } \\
\text { transferências } \\
\text { monetárias }\end{array}$ & Alimentos & Água & $\begin{array}{c}\text { Adoção do trabalho remoto } \\
\text { (home office) }\end{array}$ & $\begin{array}{l}\text { Diminuição da } \\
\text { tributação }\end{array}$ \\
\hline $\begin{array}{l}\text { Extensão das } \\
\text { existentes e } \\
\text { ampliação da } \\
\text { cobertura }\end{array}$ & Medicamentos & Eletricidade & $\begin{array}{c}\text { Proteção salarial e dos } \\
\text { postos de trabalho (seguro } \\
\text { Desemprego e licenças } \\
\text { Remuneradas, por exemplo) }\end{array}$ & $\begin{array}{c}\text { Facilidades no } \\
\text { pagamento de } \\
\text { empréstimos e } \\
\text { hipotecas }\end{array}$ \\
\hline \multirow[t]{2}{*}{$\begin{array}{l}\text { Antecipação de } \\
\text { benefícios já } \\
\text { previstos }\end{array}$} & Máscaras & Gás & & $\begin{array}{l}\text { Controle de } \\
\text { Preços }\end{array}$ \\
\hline & Álcool em gel & $\begin{array}{c}\text { Telefones, internet TV } \\
\text { por assinatura }\end{array}$ & & \\
\hline
\end{tabular}

Fonte: elaboração dos autores. 
- As parcelas da sociedade civil mais afetadas pela COVID-19 foram as seguintes: mulheres, jovens e idosos; trabalhadores informais, empregadas domésticas, população rural, povos indígenas, afrodescendentes, migrantes, pessoas em situação de rua e indivíduos com necessidades específicas;

- A participação feminina no mercado de trabalho concentra-se no setor de serviços, sobretudo em empregos domésticos. Essa atividade esteve entre as mais afetadas ao longo de 2020, em virtude do distanciamento social. 51,3\% das mulheres inseridas no mercado de trabalho encontram-se na informalidade. Como ressalta a CEPAL, as políticas públicas deveriam contemplar a dimensão de gênero. Contudo, isso ocorreu de maneira superficial, como no caso brasileiro, em que as mães solteiras ou mulheres chefes de família receberam o dobro do auxílio emergencial, que passou a ser pago pelo governo federal em abril de 2020;

- $\quad 0$ fechamento de escolas e universidades afetou aproximadamente 115 milhões de estudantes. 0 número abarca os discentes do pré-escolar ao ensino superior. Embora medidas de ensino a distância ou remoto tenham sido implementadas, a CEPAL e a UNESCO apontaram que o ineficiente ou nulo acesso aos dispositivos tecnológicos e à internet prejudicou os mais pobres, elevando as disparidades de aprendizagem entre estes e os grupos abastados das nossas sociedades, ao mesmo tempo que acentuou a evasão escolar, como apontamos em nossas considerações iniciais. Segundo as duas entidades, em 2019, 66,7\% dos latino-americanos tinham acesso à internet. 0 1/3 restante tem acesso limitado ou não o dispõe, em razão de diversos fatores, com condição econômica, social, idade ou localização geográfica;

- A elevação do desemprego e as reduções salariais (em torno de 10,1\% do PIB regional) farão com que as parcelas mais vulneráveis das nossas sociedades sejam expostas aos efeitos da pandemia. No caso dos jovens, as dificuldades no acesso a oportunidades de trabalho e de permanência nos estudos serão ampliadas. Com isso, será mitigada a possibilidade de inclusão social e laboral. Além disso, populações indígenas e afrodescendentes estão extremamente expostos aos impactos da pandemia, pois ocupam postos precários no mercado de trabalho ou por sofrem com diferenças salariais decorrentes da discriminação racial;

- Os deslocamentos inter-regionais poderão ampliar-se. Ademais, os migrantes estão entre os grupos mais expostos aos efeitos da COVID-19. 0 fechamento das fronteiras nacionais, a dependência do setor informal do mercado de trabalho, o restrito acesso aos sistemas de saúde e de proteção social e a discriminação racial, o racismo e a xenofobia representam as suas principais fragilidades desse grupo. 
Um aspecto a ser destacado nos diversos relatórios cepalinos refere-se à proposta de adoção de uma renda básica universal na região. A entidade vem continuamente recomendando a viabilização dessa política social, pois, se adotada, ela teria uma dupla consequência: contribuiria com a atividade econômica e mitigaria a vulnerabilidade dos distintos segmentos sociais, mesmo aqueles que não se encontram em situação de pobreza e extrema pobreza. Essa avaliação pode ser constatada a seguir:

Em uma perspectiva de longo prazo, a CEPAL reitera que o alcance dessas transferências deve ser permanente e contemplar pessoas não inseridas em situação de pobreza, como grupos que recebem salários baixos e médio-baixos, mas que não são pobres. Isso permitiria avançar em direção a um ingresso básico universal que deve ser implementado gradualmente em um período a ser definido a partir da situação de cada país. Esta consideração é importante, pois a superação da pandemia levará tempo e as sociedades terão que conviver com o coronavírus, algo que dificultará a reativação econômica e produtiva (tradução nossa) ${ }^{22}$.

A proposta cepalina de manutenção das transferências financeiras a grupos vulneráveis enquanto não ocorrer a vacinação em massa e a extirpação da pandemia coaduna-se com as recomendações recentemente feitas por organismos internacionais. Mesmo o Fundo Monetário Internacional (FMI), que historicamente adotou posturas contrárias à extensão do gasto público latino-americano, defende essas medidas. Em entrevista à Folha de S.Paulo, sua diretora-gerente, Kristalina Georgieva, afirmou:

0 que sabemos por experiência é que uma pandemia leva a mais desigualdades. Há uma necessidade muito premente de enfocar a questão de quem é o mais severamente impactado pela pandemia e quais opções de políticas existem para evitar que a desigualdade se aprofunde. Trabalhadores pouco qualificados, mulheres, jovens são os mais afetados e sabemos que, em todas essas três categorias, antes da pandemia havia problemas. E agora esses problemas são ampliados. Então, o que deve ser feito? Em primeiro lugar, o apoio público que agora é fornecido em uma escala muito significativa, $8 \%$ do PIB em medidas fiscais na América Latina, precisa gradualmente ser mais bem direcionado para partes da economia e trabalhadores e desempregados que estão nesta categoria mais severamente afetados (...) Muito importante para os países continuarem a apoiar as empresas e as pessoas até que haja uma saída duradoura da crise de saúde (...) não retire o suporte se você tiver capacidade, não retire o suporte até que você esteja do outro lado da crise de saúde (...) Retirar o apoio poderia significar um obstáculo para a recuperação [...] Cortar essa corda de salvamento prematuramente é um perigo para a pobreza e a desigualdade e também para o sucesso na recuperação mais rápida e robusta (...) as autoridades devem proteger os pobres e evitar um aumento acentuado da desigualdade de renda e da pobreza (Dias, 2020: A18). 
A proposta de implementação de ações estatais que protejam as franjas mais afetadas pela pandemia deriva dos alarmantes dados aferidos pela CEPAL no decurso de 2020. Segundo suas estimativas, 8 em cada 10 habitantes da região (aproximadamente 491 milhões de pessoas) ${ }^{23}$ demandam políticas públicas em razão da sua condição de vulnerabilidade aos efeitos socioeconômicos e psicológicos da COVID-19. Por isso, além de impulsionar o debate sobre a política universal de transferência de renda, a entidade elaborou as propostas abaixo elencadas ${ }^{24}$, que objetivam atenuar os impactos socioeconômicos da pandemia:

I. Auxílio básico de emergência a toda a população em situação de pobreza;

II. Bônus contra a fome para os estratos populacionais em condição de extrema pobreza;

III. Políticas sociais universais, progressivas e distributivas;

IV. Suspensão e/ou alargamento prazo para pagamento de dívidas de Micro, Pequenos e Médios empresários;

V. Redução parcial de salários em setores econômicos afetados pela COVID-19;

VI. Apoio, com condicionantes, a grandes empresas em setores estratégicos que estão em risco;

VII. Políticas fiscais e monetárias expansivas em um contexto de estabilidade macroeconômica;

VIII. Financiamento a empresas em condições favoráveis (tradução nossa).

Utilizamos, nesta parte do artigo, um conjunto de dados e análises que almejaram amparar as nossas avaliações sobre esse momento sombrio, nevoado e imprevisível. A julgar pelos acontecimentos de nossa história recente, dentre os quais destacamos o descrédito em relação aos sistemas democráticos-representativos, o fortalecimento de grupos de extrema-direita e as rebeliões populares de 2019; o período que se avizinha poderá ser marcado pela intensificação da luta social e pela instabilidade política na América Latina.

Em um momento no qual assistimos a recorrência de golpes de Estado, como na Bolívia em 201925, e o fortalecimento de organizações sociais, partidos e lideranças identificadas com práticas autoritárias que marcaram melancólicas páginas de nossa história no século XX, esperamos, com as informações aqui apresentadas, colaborar para a compreensão de um presente assustador e lúgubre em virtude da nossa situação pandêmica.

Na terceira parte deste artigo, nos dedicaremos à situação dos migrantes, grupo fortemente afetado pela COVID-19, e ao fenômeno das migrações forçadas, em especial o caso dos deslocamentos da América Central aos Estados Unidos, passando pelo México, conside- 
rado um dos corredores humanos mais importantes do mundo. Nesse trânsito de vidas, nos encontraremos com milhares de seres humanos enfrentando as adversidades e violências que o desterro Ihes impõe. 0 vírus passa a ser mais uma difícil fronteira na vida dos migrantes, dificultando e vulnerabilizando suas jornadas em busca de um melhor porvir.

\section{A PANDEMIA NÃO DETÉM OS QUE SÃO OBRIGADOS A MO- VER-SE: ATRAVESSANDO O MÉXICO A CAMINHO DA FRON- TEIRA ESTADUNIDENSE EM TEMPOS DE COVID-19}

América Latina atravessa uma crise profunda e singular provocada pela pandemia, con-
forme demonstramos. Ela provocou não só uma crise de saúde pública, mas também uma convulsão das bases sobre as quais construímos a chamada normalidade.

La incertidumbre, el trauma, la desconfianza, y el desconcierto asociado a la vivencia colectiva de la situación han convivido con el despliegue de espacios y tiempos de excepcionalidad destinados a paliar los efectos de la pandemia. Estados de alarma y de emergencia han reacomodado la vida cotidiana en forma de cuarentenas, aislamientos, restricciones a la movilidad, cierre de fronteras (Lois, 2020: 294).

0 fechamento das fronteiras e o confinamento social, em decorrência da pandemia, potencializaram as condições de precariedade e de vulnerabilidade vividas por muitas pessoas migrantes, ferindo os direitos humanos de milhões de indivíduos submersos em meio à guerra dos muros - já existente - e à guerra epidemiológica. 0 contexto da pandemia fez com que milhares de pessoas em movimento buscassem as rotas clandestinas e se vissem desprovidas das medidas de proteção, saúde e segurança proporcionadas pelos Estados, ações das quais estavam excluídas por sua condição de indocumentados. Dessa maneira, a migração e a pandemia apresentam-se como uma crise dentro da outra.

A militarização das fronteiras e a segurança do estado, algo já existente nas políticas dos Estados-nações, potencializam-se, com a emergência sanitária. A securitização é o processo mediante o qual um ator com certo poder e influência constrói um fenômeno percebido como ameaça existencial, ou seja, considerar certo fenômeno uma ameaça depende da percepção e dos interesses que os atores do sistema internacional perseguem. Sendo assim, a ameaça pode cair em considerações subjetivas. Isso não é uma situação alheia à imigração como fenômeno social, se pensarmos que os Estados, os indivíduos e as instituições podem considerar um fenômeno migratório algo positivo ou negativo, com base às suas percepções e identidades. Por exemplo, os casos dos fluxos migratórios massivos, que representam um desafio para os Estados (Buzan e Hansen, 2012). 
Trata-se do poder do Estado quando ele atua fora de seu domínio territorial e de sua soberania e, dessa forma, materializa a soberania do império. Estamos falando da externalização das fronteiras, do hipernacionalismo e da militarização. Por exemplo, na sua campanha eleitoral de 2016, Trump repetiu várias vezes, sem economizar nas palavras: "Quero construir o muro, temos que construir o muro... México pagará pelo muro, mesmo que eles ainda não saibam". A construção do prometido muro "grande e suntuoso" que deveria ter 3.142 km de fronteira nunca chegou a se concretizar. As obras se limitaram a 507 km de barreira, em sua maioria formada por obstáculos já existentes. Pode-se dizer que a verdadeira muralha de Trump foi outra, uma bem menos perceptível, mas com impacto direto em milhões de pessoas, a maioria delas centro-americanas, como foi o acordo com o México em 2019 para impedir a entrada de imigrantes nos Estados Unidos (Sánchez, 2020). As palavras direcionadas aos migrantes mexicanos, por Trump, tachando-os de população criminosa, ecoou em muitas partes do mundo. Dessa forma, o dirigente máximo dos Estados Unidos criminalizou os fluxos migratórios e permitiu avançar uma política da governamentalidade migratória globalizada que articula o direito ao movimento como chave fundamental de produção de desigualdades na ordem capitalista contemporânea.

A política anti-imigrantista de Donald Trump é o máximo exemplo da militarização, da hipernacionalização e da externalização da fronteira potencializada com o surgimento da pandemia. O mandatário estadunidense, em comum acordo com o presidente mexicano, André Manuel López Obrador, a partir do ano de 2019, transformou o México no muro dos Estados Unidos em um extenso corredor humano, estendendo suas fronteiras até a Guatemala, com o intuito de impedir que as pessoas entrassem em solo estadunidense, principalmente aqueles indivíduos que Trump considera criminosos, os que se encontram abaixo do Rio Bravo, como os latinos, os mexicanos, os povos do Triângulo Norte (Guatemala, Honduras e El Salvador), os negros do Haiti, etc.

0 chamado programa Quédate en México (Permaneça em México) começou a funcionar após janeiro de 2019, depois que Trump ameaçou impor taxas aos produtos mexicanos. Desde então, o governo do México enviou a sua Guarda Nacional às fronteiras sul e norte, permitindo que os Estados Unidos encaminhassem mais de 70 mil pessoas ${ }^{26}$ para território mexicano ${ }^{27}$. A suspensão, devido à pandemia, das audiências perante as cortes migratórias estadunidenses ampliou, por tempo indeterminado, a multiplicidade de situações de risco vividas pelos imigrantes no México. Organizações pró-imigrantes denunciaram frequentemente que tanto os Estados Unidos quanto o México foram omissos quanto aos migrantes, pois não criaram medidas mínimas para a prevenção ou a diminuição dos riscos sociais e de contágio da COVID-19. Em razão disso, colocaram-se em risco a integridade, a saúde e outros direitos humanos das pessoas migrantes e solicitantes de asilo ${ }^{28}$. 
A pandemia não freou, em absoluto, o fluxo de migrantes rumo aos Estados Unidos e, consequentemente, as suas deportações. A migração sul-norte cresceu mês a mês desde abril de 2020, período auge da COVID-19 naquele país, quando ocorreram 17.106 mil detenções. 0 número de migrantes, assim como o número de mortos pela pandemia, só aumentou: 23.237 no mês de maio, 33 mil em junho, 40 mil em julho; em agosto foram 50 mil e em setembro, 57 mil. 0 Departamento de Alfândegas e Proteção Fronteiriça dos Estados Unidos (CBP são as siglas em inglês) reportou que nos meses de outubro e novembro foram capturadas 9.128 crianças que viajavam sozinhas e 116.935 adultos que pretendiam migrar sozinhos. Segundo Eunice Rendón, diretora de Agenda Migrante, apesar da pandemia, as pessoas começaram a sair e já começam a retomar o tema da migração a Estados Unidos, e a cada mês o fluxo aumenta e certamente crescerá em $2021^{29}$.

0 próprio CBP, no mês de agosto de 2020, defendeu as chamadas "deportações express" e culpou os imigrantes pelo avanço do coronavírus nos Estados Unidos. 0 chefe da Oficina de Alfândega e Controle Fronteiriço, Mark Morgan, defendeu as "deportações express" e aproveitou a apresentação dos dados mensais de sua agência para chamar de irresponsáveis os migrantes que tentam entrar no país sem autorização durante a pandemia. Segundo Morgan, apesar do perigo que representa a COVID-19, a imigração ilega ${ }^{30}$ continua e coloca em risco a vida dos estadunidenses. Os migrantes continuam ignorando as ordens de seus países de permanecer em casa e a orientação dos médicos experts de todo o mundo ${ }^{31}$. Tomando como base as palavras utilizadas pelo chefe do CBP, encontramos imediatamente discurso que criminaliza e culpabiliza os migrantes. Primeiramente, quando ele considera a imigração como um ato "ilegal", como se todo indivíduo que não estivesse regularizado ou documentando conforme a legislação do estado fosse um criminoso. Nenhum ser humano é ilegal. Em todo caso, é indocumentado. Segundo, ele afirma que os migrantes "ignoram as ordens de seus países de permanecerem em casa", como se a migração fosse uma aventura ou uma opção, e os fatores de expulsão dos estados de origem dos fluxos migratórios não obrigassem as pessoas a deixarem suas casas de maneira desesperada, até mesmo em plena emergência sanitária. Por último, acusa os migrantes de serem portadores de doença, quando, na verdade, são tão vítimas quanto qualquer pessoa, ou, até mais, por se encontrarem em condições de extrema vulnerabilidade, sem o devido acolhimento humanitário.

Enquanto esperam nas fronteiras pelo asilo que nunca chega, os imigrantes estão expostos a todo tipo de violência, muitos sem condições de higiene em plena pandemia e sem acesso a advogados que os defendam. Nessas migrações sul-norte, foram contabilizadas 256 crianças que foram vítimas de sequestro e tentativa de sequestro ${ }^{32}$. Esses seres humanos vivem no limbo, em um eterno trânsito, obstaculizados em sua travessia, enfrentando mais um inimigo: a pandemia. 
Claro está que esses fluxos migratórios são originários das condições estruturais de cada país. No caso dos centro-americanos, eles são privados da possibilidade de permanecer em seus países. A população que vive em condições de pobreza e marginalização, ademais de carecer de bens econômicos para subsistir, está privada de bens socioculturais e vive uma grande privação política. Em condições reais, carecem de condição de cidadania e de mecanismos de identificação com seus governos, instituições e o resto da população. A situação de delinquência e de violência social dá-se principalmente por meio de grupos urbanos armados que dominam bairros inteiros devido à ausência de instituições governamentais e privadas que integrem positivamente os cidadãos, principalmente os pertencentes à infância e à juventude. Apesar de viverem formalmente sob governos democráticos, as estruturas das administrações públicas de El Salvador, Guatemala e Honduras carecem de orçamentos e projetos educativos e de integração social (Manaut, 2015). Dessa forma, a opção de organização violenta em bandas armadas é o único vínculo de identidade que têm muitos dos jovens nascidos nesses países. São países de Estado mínimo, de economia neoextrativista, de uso depredatório dos recursos naturais, de uso da força do Estado e da violência para conter mobilizações sociais, e até para conter os migrantes, como é o caso das fronteiras do sul do México com a Guatemala. É uma política da morte, sem dúvida, que exclui os cidadãos de poder subsistir e viver sem violência dentro do seu próprio Estado. Os indivíduos não podem retornar pelas ameaças que sofrem dos grupos armados, e os Estados não querem se encarregar dessas vidas. Então, elas são descartadas e a migração é o símbolo desse despejo.

No contexto da pandemia, a vulnerabilidade dessa população migrante aumentou consideravelmente. Os fatores que antes colocavam em risco a vida dessas pessoas se incrementaram pela falta de oportunidades e pela redução das redes de apoio. Por exemplo, muitos migrantes veem-se obrigados a passar as noites em espaços insalubres, por falta de recursos monetários suficientes para alugar um quarto e pelo aumento da demanda de espaço disponível nos albergues que os acolhem nos caminhos. Por conseguinte, essa e outras situações acabam por reduzir consideravelmente as opções para seguir as medidas de emergência sanitária.

Outro grave problema que envolve a situação dos migrantes em tempos de pandemia são os confinamentos nos centros de detenção e os transtornos mentais em consequência dessas estadas. Vivendo em condições insalubres se incrementa o risco de contrair o vírus. Em alguns casos, os migrantes reclamaram de uso excessivo da força, agressão sexual e confinamento solitário inadequado utilizados como formas de castigo. A estada prolongada nos centros de detenção provoca grande trauma, aflição física e psicológica e transtorno mental nas pessoas migrantes ${ }^{33}$. 
As detenções migratórias implicam privação de liberdade sob o eufemismo de "alojamento" e representam interesses do governo dos Estados Unidos no controle fronteiriço. A Lei de Migração mexicana estabelece que a partir do Controle Migratório se fiscalize se as pessoas que entram no país contam com documentação necessária para realizar uma estada prolongada no México, e a detenção migratória não deve exceder as 36 horas. Por outro lado, os processos de deportação têm de ocorrer em um prazo de 15 dias depois da apresentação do migrante. Nesse ato, informa-se a pessoa o motivo pelo qual ela foi privada de liberdade, faz-se a leitura de seus direitos e encaminha-se o migrante a um alojamento ou centro de detenção. Entretanto, não é isso o que tem acontecido. Os imigrantes têm vivido em condições adversas nos centros de detenção, sofrendo diferentes tipos de violência ${ }^{34}$.

As organizações e a sociedade civil têm se manifestado em prol das pessoas migrantes, exigindo soluções para a definição daqueles que se encontram em condição de solicitação de refúgio e também pela eliminação do programa Quedáte en México. 0 relatório da Fundación para la Justicia y el Estado Democrático de Derecho, publicado em dezembro de 2020, alerta para as obrigações em matéria de direitos humanos dos Estados Unidos e do México:

El Estado mexicano y EUA tienen obligaciones en materia de derechos humanos con la población migrante y sujeta al Programa Quédate en México, especialmente en materia de salud, libertad personal, integridad personal, derecho a buscar y recibir asilo. En este sentido -y mientras persiste el programasse hace imperativo que los Estados adopten medidas orientadas a respetar los derechos de las personas sujetas al Programa Quédate en México, atendiendo a los exhortos de la Alta Comisionada de las Naciones Unidas para los Derechos Humanos, el Alto Comisionado de las Naciones Unidas para los Refugiados, la Organización Internacional para las Migraciones y la Organización Mundial de la Salud ${ }^{35}$.

Para que o programa Quédate en México seja eliminado de forma coerente, é necessário que o governo do presidente eleito, Joe Biden, realize essa ação não só em coordenação com o governo mexicano, mas também com organizações da sociedade civil, albergues para pessoas migrantes e com outros atores, para que, dessa forma, se assegure que existam as melhores condições em ambos os lados da fronteira mexicana. As negociações referentes às migrações entre o novo líder do executivo estadunidense e o mexicano já começaram. E a esperança é que as políticas anteriores sejam desmontadas e que se termine com o degradante programa Quédate en México. É um tema de máxima relevância, não pode esperar. Joe Biden deixou claro que seu governo tem como prioridade o tema migratório, como não poderia deixar de ser. As pessoas continuarão se movendo, porque migrar é um direito humano, ainda que muitos não saibam ou hesitem em não querer saber. 
Portanto, novamente se coloca em pauta o voltar-se para os países expulsores, de onde saem as milhares de pessoas, no intuito de ajudar a desenvolver as economias, reduzir a violência e melhorar a vida de suas populações ${ }^{36}$.

Claro está que as políticas anti-imigratórias do governo de Donald Trump, em parceria com o governo mexicano de Andrés Manuel López Obrador, ficarão marcadas na história como uma terrível sucessão de violação dos direitos humanos das pessoas migrantes, não aliviadas nem sequer em época de pandemia.

Espera-se escrever uma nova história das migrações com o próximo governo estadunidense, e as comunidades latino-americanas que o apoiaram seguirão vigilantes, para que os traumas e as atrocidades cometidas não se repitam nos próximos anos. Algo de esperança brota, pois as sementes sempre permanecem.

\section{CONSIDERAÇÕES FINAIS}

pandemia decorrente do SARS-CoV-2 desnudou os efeitos sociais e econômicos deri-
vados de quatro décadas de aplicação do doutrinário neoliberal. A vulnerabilidade de variados segmentos sociais ficou exposta ao longo de 2020 e, como consequência, muitos dos apologistas do neoliberalismo passaram a defender políticas sociais que atenuassem a condição de miséria da maioria da população mundial.

Como examinamos ao longo deste artigo, os efeitos da COVID-19 não são democráticos. 0 vírus atingiu de forma mais veemente os grupos mais expostos, seja pelas condicionantes de sua inserção no mercado de trabalho, ou pela sua precária situação social. Como examinamos, o caso latino-americano é emblemático, em virtude das características da sua formação econômica e históricas mazelas sociais.

Entre os grupos mais vulneráveis, encontra-se a população migrante da América Latina. São vítimas da violência, dos desastres climáticos, das más condições econômicas de seus países e da falta de oportunidades e expectativas de futuro que não lhes brinda a política de seus Estados. As migrações não constituem um fator novo, claro está, mas a pandemia trouxe para esses indivíduos em trânsito mais um muro a combater: o epidemiológico. A crise sanitária serviu como um instrumento a mais para os Estados-nações salvaguardarem suas fronteiras e recrudescerem a militarização de seus territórios, mesmo conhecendo os direitos dos solicitantes de refúgios, cientes de que a saúde é benefício de todos, e não privilégio de algumas nacionalidades. Como demonstramos ao longo do artigo, a pandemia responsabilizou os migrantes pela sua condição, condenou-os ao limbo, ao trânsito permanente, ao nunca chegar. Por outro lado, a resistência migrante também demonstrou ao mundo da pandemia o 
quanto eles são necessários, arriscando suas vidas nos serviços essenciais, enviando remessas às famílias distantes em situações dramáticas e de necessidades vitais. Muitos dos nossos países contaram com as contribuições financeiras, ao longo da pandemia, enviadas pelos migrantes, como é o caso do México.

Além da perpetuação do fenômeno da migração na América Latina, cremos na tendência de que a acentuação da crise econômica, iniciada em 2014, e o aumento da pobreza, conforme apontamos, podem alavancar o descontentamento social dos latino-americanos. Nesse quadro, a descrença com as nossas democracias e a instabilidade política podem intensificar-se, levando a novas ondas de rebeliões populares, como as ocorridas em 2019. Dessa forma, acreditamos que, mais do que nunca, a imprevisibilidade política margeia o futuro da região.

\section{NOTAS}

1 Sobre o ciclo de exportação das commodities entre 2003 e 2013 e o seu esgotamento, ver: Martins (2011) e Webber (2019).

2 The Economist (2009).

3 Corporación Latinobarómetro (2018: 35).

4 Comissão Econômica para a América Latina e Caribe (2020a, p. 97).

5 Comissão Econômica para a América Latina e Caribe (2020a: 123; 2020b: 97).

6 Segundo Pasquino, entre outras características, as rebeliões ou revoltas populares caracterizam-se pela ausência de proposição de subversão da ordem constituída e almejam a satisfação imediata de demandas políticas e econômicas. Para fins desse artigo, nos apropriamos dessa definição. Ver: Pasquino (1998: 1121).

7 Análises aprofundadas dessas rebeliões podem ser vistas em Fiori (2019) e Wasserman (2020).

8 Vassalo (2020).

9 Rojas (2020).

10 Comissão Econômica para a América Latina e Caribe (2020c: 15).

11 Comissão Econômica para a América Latina e Caribe (2020a: 11, 125).

12 Comissão Econômica para a América Latina e Caribe (2020c: 17). Na Tabela 2 apresentamos os dados sociais por país. Como poderá ser observado, infelizmente, a pandemia aprofundou as desigualdades sociais em nossa região ao longo de 2020.

13 The World Bank (2020).

14 Oppenheimer (2020). 
15 Sobre esses protestos, consultar: Lacurcia (2020) e Colombo (2020).

16 Patu (2020: A17-18).

17 Comissão Econômica para a América Latina e Caribe (2020a: 12).

18 Dias (2020).

19 Os oito itens expostos sinteticamente nessa parte do artigo foram elaborados a partir da leitura dos seguintes relatórios: Comissão Econômica para a América Latina e Caribe (2020d: 3, 6-8), Comissão Econômica para a América Latina e Caribe e Organização Internacional do Trabalho (2020: 20, 27-28), Comissão Econômica para a América Latina e Caribe (2020e: 2) e Comissão Econômica para a América Latina e Caribe (2020a: 51).

20 Comissão Econômica para a América Latina e Caribe (2020c: 11).

21 Comissão Econômica para a América Latina e Caribe (2020d: 8).

22 Comissão Econômica para a América Latina e Caribe (2020d: 15).

23 Comissão Econômica para a América Latina e Caribe (2020d: 20).

24 Comissão Econômica para a América Latina e Caribe (2020d: 23).

25 Sobre o golpe de Estado ocorrido na Bolívia em 2019, ver: Stefanoni (2019) e Moldiz (2020).

26 Dados da Organização Mundial da Saúde.

27 Arroyo (2020: 3).

28 Moncada (2020).

29 Butron (2020).

30 Termo usado por Mark Morgan, do qual totalmente discordamos, pois nenhuma vida migrante é ilegal.

31 Redacción (2020).

32 Syracuse University TRAC Immigration Data Tools (última atualização: 4 de novembro de 2020). Disponível em: <https://trac.syr.edu/immigration/>. Acesso em: 18 dez. 2020; Human Rights First (última atualização: 4 de maio 2020) Disponível em: <https://www.humanrightsfirst.org/>. Acesso em: 18 dez. 2020.

33 Aguilar-Gaxiola et al. (2020).

34 Ramírez (2020).

35 Moncada (2020: 9).

36 Arroyo (2020, p. 3) e Román e Jímenez (2020). 
Conflitos de interesse: nada a declarar.

Fonte de financiamento: Bolsa Jovem Cientista do Nosso Estado e Produtividade CNPQ.

Contribuição dos autores: Araujo, R.: Escrita do Texto, Levantamento Bibliográfico e de Fontes, Análise. Sarmiento, E.: Escrita do Texto, Levantamento de Fontes, Análise.

\section{REFERÊNCIAS BIBLIOGRÁFICAS}

AGUILAR-GAXIOLA, S. et al. El impacto de COVID-19 en la salud mental de migrantes y solicitantes de asilo. In: FUNDACIÓN FRIEDRICH NAUMANN. Migración en tiempos de pandemia. 10 perspectivas para repensar el fenómeno en México. Centroamérica y Estados Unidos. p. 10. (e-book, obra coletiva).

ARROYO, L. Biden y López Obrador acercan posiciones sobre inmigracion. El País, 21 dez. 2020, p. 3.

BUTRON, J. Migración ilegal a EU, la más alta em 14 meses y tema de charla AMLO-Biden. La Razón, 21 dez. 2020, p. 14.

BUZAN, B.; HANSEN, L. A evolução dos estudos de segurança internacional. São Paulo: UNESP, 2012.

CALAZANS, M. E.; MALOMALO, B.; PIÑEIRO, E. S. Apresentação. In: CALAZANS, M. E.; MALOMALO, B.; PIÑEIRO, E. S (orgs.). As desigualdades de gênero e raça na América Latina no século XXI. Porto Alegre: Editora Fi, 2019.

COLOMBO, S. Crises locais eclipsam quadro de COVID grave mas estável na América Latina. Folha de S.Paulo, 26 set. 2020 , p. A16.

COMISSÃO ECONÔMICA PARA A AMÉRICA LATINA E CARIBE. Balance Preliminar de las Economías de América Latina y el Caribe. 2019. Disponível em: <https://www.cepal.org/es/publicaciones/45000-balancepreliminar-economias-america-latina-caribe-2019>. Acesso: 10 mar. 2020.

COMISSÃO ECONÔMICA PARA A AMÉRICA LATINA E CARIBE. Panorama Social de América Latina 2019. Santiago: CEPAL, 2020a.

COMISSÃO ECONÔMICA PARA A AMÉRICA LATINA E CARIBE. Balance Preliminar de las Economías de América Latina y el Caribe. Santiago: CEPAL, 2020b.

COMISSÃO ECONÔMICA PARA A AMÉRICA LATINA E CARIBE. Enfrentar los efectos cada vez mayores del COVID-19 para una reactivación con igualdad: nuevas proyecciones. Santiago: CEPAL, 2020c.

COMISSÃO ECONÔMICA PARA A AMÉRICA LATINA E CARIBE. El desafío social en tiempos del COVID-19. Santiago: CEPAL, 2020d.

COMISSÃO ECONÔMICA PARA A AMÉRICA LATINA E CARIBE. Universalizar el acceso a las tecnologías digitales para enfrentar los efectos del COVID-19. Santiago: CEPAL, 2020e.

COMISSÃO ECONÔMICA PARA A AMÉRICA LATINA E CARIBE; ORGANIZAÇÃO INTERNACIONAL DO TRABALHO. Coyuntura Laboral en América Latina y el Caribe - El Trabajo en tiempos de pandemia: desafíos frente a la enfermedad por coronavirus (COVID-19). 2020. Disponível em: <https://www.cepal.org/es/ publicaciones/45557-coyuntura-laboral-america-latina-caribe-trabajo-tiempos-pandemia-desafios-frente>. Acesso em: maio 2020. 
CORPORACIÓN LATINOBARÓMETRO. Informe Latinobarómetro. 2018. Disponível em: <https://www. latinobarometro.org/latdocs/INFORME_2018_LATINOBAROMETRO.pdf>. Acesso: 12 dez. 2018.

DIAS, M. Fim prematuro do auxílio pode prejudicar recuperação do Brasil. Entrevista com Kristalina Georgieva. Folha de S.Paulo, 16 dez. 2020, p. A18.

FIORI, J. L. A revolta latina, a crise americana e o desafio progressista. Disponivel em: <https://www. brasildefato.com.br/2019/12/06/artigo-or-a-revolta-latina-a-crise-americana-e-o-desafio-progressista>. Acesso: 10 dez. 2019.

LACURCIA, L. As tensões da pandemia reativam protestos na América Latina. Disponível em: <https:// www.cartacapital.com.br/mundo/as-tensoes-da-pandemia-reativam-protestos-na-america-latina/>. Acesso em: 25 jul. 2020.

LOIS, M. Los Estados cierran sus territorios por seguridad... pero los virus están emancipados de las fronteras. Geopolítica(s), v. 11, n. especial, p. 293-302, 2020. https://doi.org/10.5209/geop.69370

MANAUT, R. B. Centroamérica geopolítica, militarización y crisis humanitária. Revista del Centro Andino de Estudios Internacionales, v. 15, p. 212-239, 2015.

MARTINS, C. E. Globalização, dependência e neoliberalismo na América Latina. São Paulo: Boitempo Editorial, 2011.

MOLDIZ, H. Golpe de Estado en Bolívia - La Soledad de Evo Morales. La Paz: OceanSur, 2020.

MONCADA, A. Informe de Investigación "En la boca del Lobo". Contexto de riesgo y violaciones a los derechos humanos de personas sujetas ao programa Quédate em México. Fundación para la Justicia y el Estado Democrático de Derecho (FJEDD). 2020. Disponível em: <https://imumi.org/attachments/2020/ Informe-En-la-boca-del-lobo-Protocolo-Quedate-en-Mexico.pdf>. Acesso em: 12 dez. 2020.

OPPENHEIMER, A. Opinión, 16 dez. 2020. Disponivel em: https://www.abc.com.py/opinion/2020/12/16/lacatastrofe-educativa-de-america-latina/. Acesso em: 16 dez. 2020.

PASQUINO, G. Revolução. In: BOBBIO, N.; MATTEUCCI, N.; PASQUINO, G. Dicionário de Política. 11. ed. Brasília: Editora da UnB, 1998. p. 1121-1131.

PATU, G. Enquanto Brasil cresce apenas 2,2\% na década, mundo avança 30,5\%. Folha de S. Paulo, 20 dez. 2020, A17-18

QUIJANO, A. Colonialidade do poder, eurocentrismo e américa latina. In: LANDER, E. (org.). A colonialidade do saber: eurocentrismo e ciências sociais. Perspectivas latino-americanas. Buenos Aires: Consejo Latinoamericano de Ciencias Sociales, 2005. p. 227-278.

RAMÍREZ, R. P. Iberopuebla, 22 out. 2020. Disponível em: <https://www.iberopuebla.mx/noticias_y_eventos/ noticias/centros-migratorios-en-mexico-violentan-proceso-de-retorno-y-derechos>. Acesso em: 20 dez. 2020.

REDACCIÓN. CBP defiende "deportaciones exprés" y culpa a inmigrantes de avance del coronavirus en EE.UU. La Opinión, 6 ago. 2020; Disponivel em: <https://laopinion.com/2020/08/06/cbp-defiende-deportacionesexpres-y-culpa-a-inmigrantes-de-avance-del-coronavirus-en-ee-uu/>. Acesso em: 21 dez. 2020.

ROJAS, B. C. Alcaldesa de Vinto: identifiqué a 10 agresores; policía no me ayudó. Disponível em: $<$ https://www.opinion.com.bo/articulo/cochabamba/alcaldesa-vinto-identifique-10-agresores-policiaayudo/20200115002645746036.html>. Acesso: 25 jan. 2020. 
ROMÁN, J. A.; JIMÉNEZ, N. Biden dispuesto a apoyar a Centroamérica y al sur de México, afirma AMLO. La Jornada, 22 dez. 2020. <https://www.jornada.com.mx/2020/12/22/politica/003n2pol>. Acesso em: 22 dez. 2020.

SÁNCHEZ, G. La politica migratoria de Trump: qué ha hecho y quién ha sufrido. 2020. Disponível em: <https://www. eldiario.es/desalambre/politica-migratoria-trump-hecho-sufrido_1_6375282.html>. Acesso em 03 nov. 2020.

STEFANONI, P. Biblias, balas y votos. Viento Sur, 21 nov. 2019. Disponível em: <https://vientosur.info/spip. php?article15323>. Acesso: 23 nov. 2019.

THE ECONOMIST. Brazil takes off. Disponível em: <https://www.economist.com/leaders/2009/11/12/braziltakes-off>. Acesso em: 14 nov. 2009.

THE WORLD BANK. Realizing the future of learning: from learning poverty to learning for everyone, everywhere. Disponivel em: <https://www.worldbank.org/en/topic/education/publication/realizing-future-oflearning-from-learning-poverty-to-learning-for-everyone-everywhere>. Acesso em: 05 dez. 2020.

VASSALO, G. ¿Qué es la Resistencia Juvenil Cochala? Disponível em: <https://www.pagina12.com.ar/246636que-es-la-resistencia-juvenil-cochala>. Acesso em: 20 abr. 2020.

WASSERMAN, C. OUTUBRO REBELDE: eleições e protestos na América Latina. Revista Eletrônica da ANPHLAC, v. 20, n. 28, p. 402-419, jan./jul., 2020. https://doi.org/10.46752/anphlac.28.2020.3862

WEBBER, J. Mercado mundial, desarrollo desigual y patrones de acumulación: la política económica de la izquierda latinoamericana. In: GAUDICHAUD, F.; WEBBER, J.; MODONESI, M. Los gobiernos progresistas latinoamericanos del siglo XXI - Ensayos de Interpretación Histórica. UNAM, 2019. p. 97-180. 